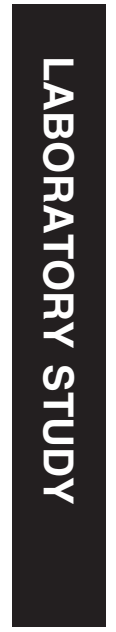

\section{Organ-cultured corneal grafts from septic donors: a retrospective study}

\begin{abstract}
Purpose To evaluate the quality of corneal grafts from donors, who have died from septic multi-organ failure and who are called septic donors in the following.

Methods One hundred and eighty-two corneal grafts from septic donors were stored in organ culture for 10-14 days. Graft evaluation was performed according to the criteria of the European Eye Bank Association. Only donor corneas with cell density values above 2000 cells $/ \mathrm{mm}^{2}$ were transplanted. Ninety-one patients who received these transplanted corneas were examined retrospectively with special emphasis on endophthalmitis, graft failure and incidence of immune reactions.

Results Ninety-one of 182 donor corneas (50\%) from septic donors were discarded mainly due to endothelial damage $(61 ; 67 \%)$. Only seven $(8 \%)$ were discarded due to medium contamination. In contrast, 452 of 1261 donor corneas (36\%) from non-septic donors during the same period were discarded, again mainly due to endothelial damage (264; 58\%). In this group, 48 donor corneas $(\mathbf{1 1 \%})$ were discarded due to medium contamination. No patient who had received a graft from a septic donor has experienced endophthalmitis. The rate of immune reactions and graft failure was in the same range when compared to a larger group who received grafts from non-septic donors.

Conclusion Our data reveal no contraindication against the use of corneal grafts derived from septic donors, critical graft assessment in organ culture provided. Eye (2002) 16, 622-627. doi:10.1038/ sj.eye. 6700145
\end{abstract}

Keywords: organ culture; corneal transplantation; sepsis; endophthalmitis; immune reaction; graft failure
H Spelsberg ${ }^{1}$, T Reinhard ${ }^{1}$, U Sengler ${ }^{1}$, W Daeubener ${ }^{2}$ and R Sundmacher
Introduction

Corneal tissue obtained from septic donors is suspected to be a cause for endophthalmitis after penetrating keratoplasty. Some case reports describe endophthalmitis following keratoplasty caused by bacteria adhering to the grafts. ${ }^{1-4}$ All grafts had been stored in short-term culture at $+4^{\circ} \mathrm{C}$. Keates et al $l^{5}$ studied 10 consecutive pairs of eyes from septic donors and stored one cornea of each pair in McCarey-Kaufman medium $\left(+4^{\circ} \mathrm{C}\right)$ containing 100 units penicillin and streptomycin per milliliter for $24 \mathrm{~h}$ and the other one in moist chamber $\left(+4^{\circ} \mathrm{C}\right)$ for 3 days. Seven of the 20 corneas $(35 \%)$ were shown to have bacterial contamination in contrast to 25 corneas from non-septic donors stored in McCareyKaufman medium with negative cultures. ${ }^{5}$ However, a direct relationship between the corneal contamination and the systemic infection of the donor could not be shown. ${ }^{5}$ It was suggested that contamination of corneal tissue may occur via the aqueous or limbal circulation. ${ }^{6}$ In contrast, Clark et al could demonstrate that aqueous humor is usually sterile in septic patients: no sample of aqueous humor from 50 septic cadavers was contaminated. ${ }^{6}$ Contamination via the normal conjunctiva flora seems to be more likely since Polack et al found all smears of 240 cadaver eyes contaminated by bacteria. ${ }^{7}$ Pathogens were similar to the ocular flora of the living eye but increased in the eye of a cadaver.?

Up to now only reports about corneal grafts from septic donors stored in short-term culture at $+4^{\circ} \mathrm{C}$ have been published. Since long-term organ culture at $+30-37^{\circ} \mathrm{C}$ is routinely performed in most cornea banks of the European Eye Bank Association, ${ }^{8}$ we conducted a retrospective study concerning grafts from septic donors stored in long-term organ culture. It was the purpose of this study to find out contamination rates and to 
evaluate the clinical outcome of penetrating keratoplasty using such grafts. Corneal graft shortage still plays an important role in Germany. Therefore cornea donation should be rejected only in deceased persons with a proven risk for the recipient.

\section{Patients and methods}

\section{Graft donors}

One hundred and eight-two donor corneas from 91 septic donors were kept in long-term organ culture between April 1995 and November 1998. Seventy donors $(76.9 \%)$ died in intensive care units, 21 donors $(23.1 \%)$ deceased in wards of medical and surgical departments associated with the Heinrich-HeineUniversity. Mean donor age was 61 years (range 13-87 years). In most cases the diagnosis sepsis was a clinical one, stated by medical or surgical staff and including clinical signs like body temperature $>38^{\circ} \mathrm{C}$ or $<36^{\circ} \mathrm{C}$, tachycardia ( $>90$ beats per minute), tachypnea (with breath frequency $>20$ breaths per minute or hyperventilation with carbon dioxide pressure $<32 \mathrm{mmHg}$ ), white blood cells $>12000 / \mathrm{mm}^{3}$ or $<4000 / \mathrm{mm}^{3}$ or systolic blood pressure $<90 \mathrm{mmHg}$. ${ }^{9}$ In 19 donors (20.8\%) blood cultures were positive for bacteria. Pathogens like bacteria and fungi were detected in body fluids or secretions (tracheal, abdominal, urogenital origin or wound smears) alone or additionally to positive blood cultures in 75 donors $(63.7 \%)$. No pathogen at all could be isolated in 18 donors (19.8\%). No microbiological test at all was performed in six donors $(6.6 \%)$.

During the same time (April 1995-November 1998), 1261 donor corneas from 642 non-septic donors were stored in long-term organ culture. Two hundred and fifteen of these donors (33.5\%) died in intensive care units and $361(56.2 \%)$ in wards of medical and surgical departments associated with the Heinrich-HeineUniversity. Sixty-six donors $(10.3 \%)$ were recruited from the department of forensic medicine. Mean donor age was 64 years (range 1 day-95 years).

All septic and non-septic donors were also tested for hepatitis B antigen, hepatitis C antibody and HIV1/2 antibody.

\section{Graft storage}

All donor corneas were obtained by in situ corneoscleral excision after disinfection of the eye and the lids with polyvidone iodide $1.25 \%$ for $5 \mathrm{~min}$ and rinsing with $500 \mathrm{ml}$ of sterile water. ${ }^{10}$ Mean death-toexcision time was 12.4 (1-69) h. Grafts were stored in organ culture medium containing minimal essential medium supplemented with $100 \mathrm{IU} / \mathrm{ml}$ penicillin, $100 \mu \mathrm{g} / \mathrm{ml}$ streptomycin, $2.5 \mu \mathrm{g} / \mathrm{ml}$ amphotericin B and $2 \%$ fetal calf serum. Storage time was 10-14 days. After 7 days of storage, organ culture medium was exchanged. A $5 \mathrm{ml}$ sample was tested for microbial contamination by loading a bottle with fluid agar containing active charcoal, which was then incubated at $+37^{\circ} \mathrm{C}$ and continuously measured photometrically. If an increased flare was observed, the medium sample was spread out on culture plates, incubated and assessed for growth of pathogens. Endothelial cell morphology and density were evaluated after 7 days of storage and before transplantation using phase contrast microscopy, polaroid photography and fixedframe calculation. Only donor corneas with an endothelial cell density $>2000$ cells $/ \mathrm{mm}^{2}$ were transplanted.

\section{Keratoplasty patients}

Ninety-one penetrating keratoplasties with grafts from donors classified as septic were performed between April 1995 and November 1998. The proportion of normal-risk keratoplasties was $62.6 \%$, ie first keratoplasties in eyes without corneal vascularisation, central graft position, without a preoperative history of severe surface disorders, herpetic eye disease or glaucoma. High-risk keratoplasties were 37.4\%. Mean follow-up time for the septic donor group was $21.8 \pm 14.1$ months. Mean patient age was $57 \pm 19$ years.

Between April 1995 and November 1998, 809 penetrating keratoplasties with grafts from non-septic donors were performed. According to the above mentioned criteria, $56.6 \%$ were normal-risk keratoplasties and $53.4 \%$ high-risk keratoplasties. Mean follow-up was $25.1 \pm 16.4$ months. Mean patient age was $60 \pm 19$ years.

\section{Surgical technique and follow-up}

Graft trephination, mostly with a diameter of $7.7 \mathrm{~m}$, was performed from the endothelial side. The host cornea was trephined with a $0.2 \mathrm{~mm}$ smaller diameter from the epithelial side. The donor cornea was sewn in with a double running cross stitch nylon 10.0 suture according to Hoffmann. ${ }^{11}$

Preoperatively, no treatment was given at all. Postoperatively, all patients were treated with systemic steroids (fluocortolone $1 \mathrm{mg} / \mathrm{kg}$ body weight) tapered off within 3 weeks, with topical antibiotics (gentamicin $0.003 \%$ ointment) five times daily for 1 week and with topical steroids (prednisolone-21-acetate 1\% eye drops) five drops daily tapered off within 5 months. ${ }^{12}$ A total of $38.7 \%$ high-risk patients $(8 \%$ with grafts from septic 
donors and $92 \%$ with grafts from non-septic donors) were treated additionally with systemic immunosuppressants like cyclosporin A and/or mycofenolate mofetil for 6-12 months postoperatively. Clinical controls were scheduled after 4 and 12 months postoperatively and then annually. The first running suture was removed not before the fourth postoperative month, the second one not before the 18th postoperative month.

\section{Endothelial evaluation and statistical analysis}

Endothelial evaluation was performed using a specular microscope (Konan Noncon Robo 800, Konan Inc, Nishinomiya, Hyogo, Japan). ${ }^{13}$ For analysis of the postoperative endothelial cell loss we used a longitudinal approach resulting in an individual cell loss index per patient. The slope of the linear regression line of at least three endothelial cell density values postoperatively recorded was calculated. ${ }^{14}$ The individual cell loss index (cells $/ \mathrm{mm}^{2} \times$ day) could be determined in 39 patients with transplanted corneas from septic donors and 418 patients with transplanted corneas from non-septic donors.

For statistical analysis of donor data (discarding reasons) and of individual cell loss index, $\chi^{2}$-test (Pearson) was used. Calculation of the keratoplasty data (immune reactions and graft failure) was done using the Kaplan-Meier estimator, evaluation for statistical significance via Log-rank-test. A $P$-value below 0.05 was regarded as statistically significant.

\section{Results}

In the septic donor group 91 (50\%) donor corneas were transplanted and 91 (50\%) were discarded. In contrast, $809(64 \%)$ donor corneas in the non-septic donor group were transplanted and $452(34 \%)$ were discarded. This difference was statistically significant $(P<0.001)$.

Reasons for discarding were: endothelial damage, positive or uncertain serology, contamination of the culture medium and others, eg corneal scars (Table 1).

Table 1 Reasons for discarding donor corneas from septic and non-septic donors between April 1995 and November 1998, showing no statistically significant difference between both groups ( $P$-values given)

\begin{tabular}{lccc} 
Discarding reasons & Septic donors & Non-septic donors & P-value \\
\hline $\begin{array}{l}\text { Endothelial damage } \\
\text { Positive or uncertain }\end{array}$ & $61 / 91(67 \%)$ & $264 / 452(58 \%)$ & 0.25 \\
$\begin{array}{l}\text { serology } \\
\begin{array}{l}\text { Microbial culture } \\
\text { medium }\end{array}\end{array}$ & $7 / 91(8 \%)$ & $48 / 452(11 \%)$ & 0.29 \\
$\begin{array}{l}\text { contamination } \\
\text { Others }\end{array}$ & $3 / 91(3 \%)$ & $16 / 452(4 \%)$ & 0.60 \\
\hline
\end{tabular}

Regarding the pathogens, that caused seven medium contaminations in the septic donor group, coagulasenegative staphylococci were found in five cases and candida species in two cases. These pathogens did not correspond in any case to the pathogens isolated from the cadaver's blood or body secretion. Forty-eight contaminations were registered in the non-septic donor group. Differentiation of pathogens is given in Table 2.

During the clinical follow-up time no endophthalmitis was observed.

After 2 years follow-up, 92\% clear graft survival in the septic donor group and $96 \%$ in the non-septic donor group was observed in normal-risk patients. This difference, however, was statistically not significant $(P=0.13$; Log-rank-test, Figure 1$)$. This was also true for high-risk patients: $86 \%$ clear graft survival in the septic and 78\% in the non-septic donor group $(P=0.65$; Log-rank-test, Figure 1). Rejection free graft survival was observed in $86 \%$ in the septic and $79 \%$ in the non-septic group in normal-risk patients after 2 years follow-up (Figure 2). Again, the difference was not statistically significant $(P=0.30$; Log-rank-test, Figure 2). In high-risk patients rejection free survival was $76 \%$ for the septic and $69 \%$ for the non-septic group without any statistically significant difference $(P=0.27$; Log-rank-test, Figure 2$)$.

Without respect to risk groups mean individual cell loss index was 1.2 cells $/ \mathrm{mm}^{2} \times$ day in patients with grafts from septic donors in comparison to 1.1 cells $/ \mathrm{mm}^{2} \times$ day in patients with grafts from non-septic donors. The difference was not statistically significant $\left(\chi^{2}\right.$-test, $\left.P=0.55\right)$.

Table 2 Differentiation of pathogens isolated from contaminated organ culture media in non-septic and septic donors

\begin{tabular}{|c|c|c|}
\hline $\begin{array}{l}\text { Pathogens in contaminated } \\
\text { organ culture media }\end{array}$ & $\begin{array}{l}\text { Number non- } \\
\text { septic donors }\end{array}$ & $\begin{array}{c}\text { Number septic } \\
\text { donors }\end{array}$ \\
\hline $\begin{array}{l}\text { Coagulase-negative cocci } \\
\text { (Staphylococcus epidermidis) }\end{array}$ & 26 & 5 \\
\hline $\begin{array}{l}\text { Gram-negative rod bacteria } \\
\text { (Acinetobacter, Pseudomonas } \\
\mathrm{sp} \text {, Serratia sp) }\end{array}$ & 5 & \\
\hline $\begin{array}{l}\text { Other gram-positive cocci } \\
\text { (Enterococcus sp, } \\
\text { Staphylococcus aureus) }\end{array}$ & 3 & \\
\hline Fungi & 6 & 2 \\
\hline $\begin{array}{l}\text { Suspected local corneal } \\
\text { contamination without } \\
\text { pathogen proof }\end{array}$ & 3 & \\
\hline $\begin{array}{l}\text { Muddy culture medium } \\
\text { without pathogen proof }\end{array}$ & 5 & \\
\hline Total & 48 & 7 \\
\hline
\end{tabular}


normal-risk

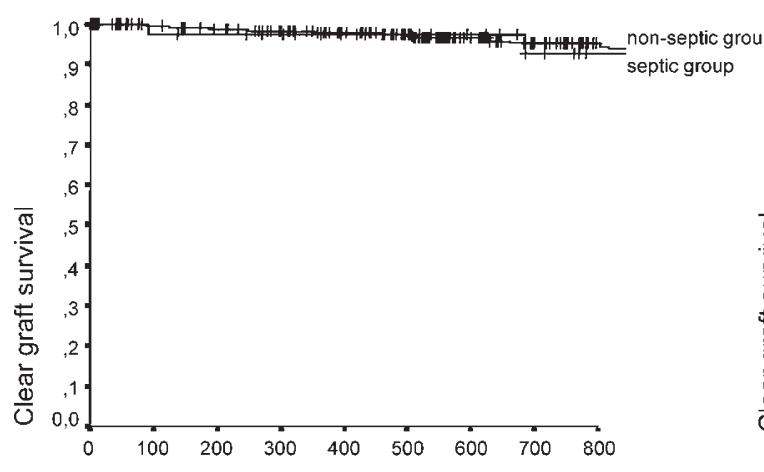

Days since Kp high-risk

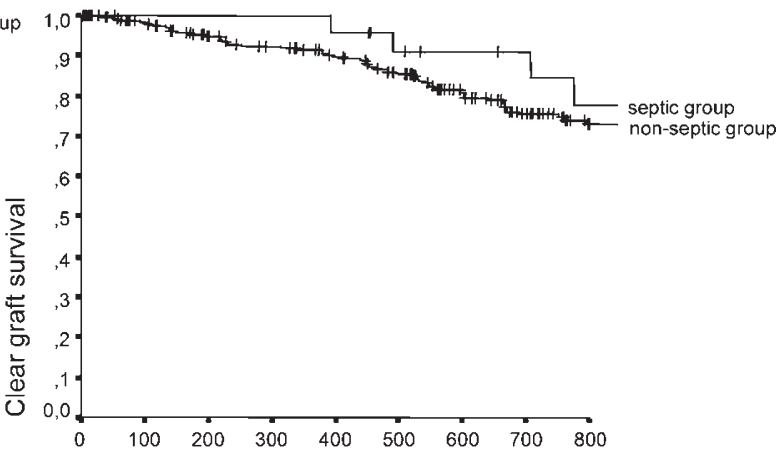

Days since $\mathrm{Kp}$

Figure 1 Clear graft survival over time in normal-risk and high-risk patients comparing septic and non-septic donors using KaplanMeier estimation. Log-rank-test: $P$-value normal-risk group $0.13 ; P$-value high-risk group 0.65 .
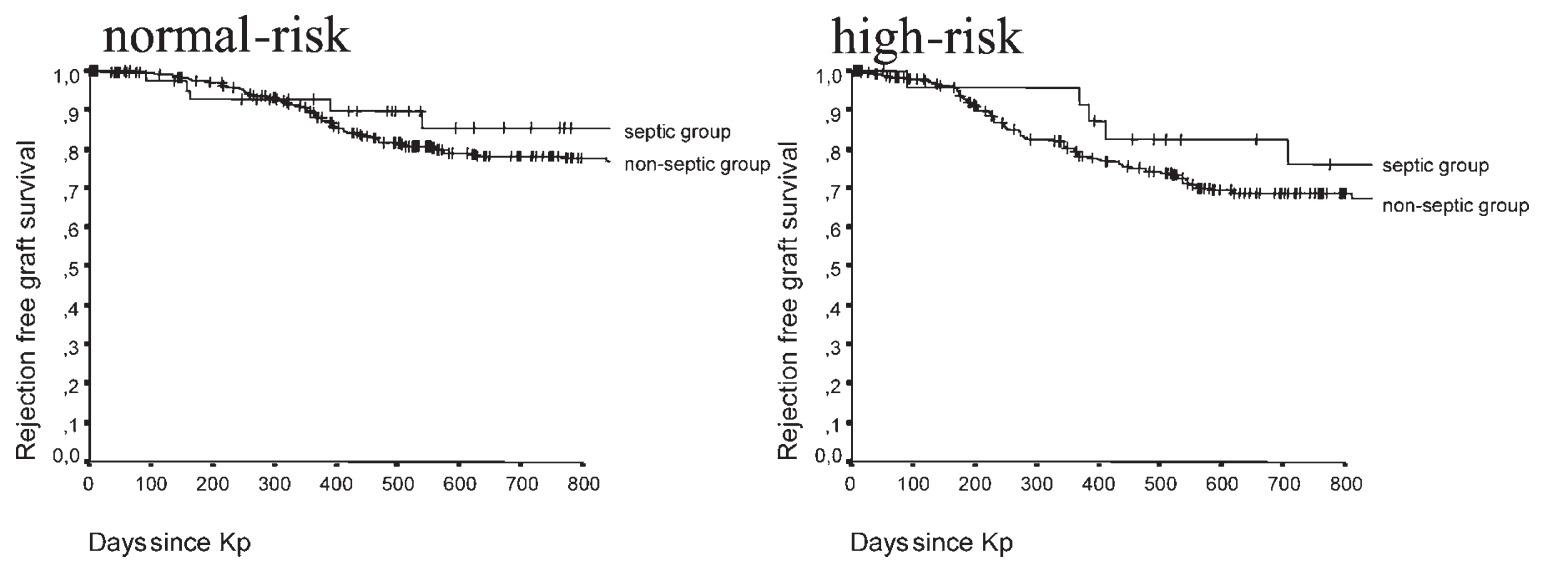

Figure 2 Rejection free graft survival over time in normal-risk and high-risk patients comparing septic and non-septic donors using Kaplan-Meier estimation. Log-rank-test: $P$-value normal-risk group 0.30; $P$-value high-risk group 0.27.

\section{Discussion}

Short-term organ culture is a common storage technique for human corneal grafts: donor corneas are stored at $+4^{\circ} \mathrm{C}$ in McCarey-Kaufman medium or related media for up to 7 days. Main disadvantages are the non-physiologic metabolic arrest before grafting and the susceptibility for non-detectable medium contamination and therefore transmissible infection due to the low storage temperature. That is why corneal grafts from septic donors stored at $+4^{\circ} \mathrm{C}$ have always been suspected of inducing endophthalmitis after penetrating keratoplasty. Endophthalmitis after grafting of short-term stored donor corneas has indeed been reported several times. ${ }^{1-4}$ In short-term storage antibiotics in the medium have only little effect, since transmitted pathogens do mostly not grow at $+4^{\circ} \mathrm{C}$. In order to protect the recipient from a transmitted endophthalmitis, higher concentrations of antibiotics in the medium were chosen, which are supposed to be absorbed by the donor cornea during storage and to be emitted after keratoplasty in the recipient's anterior eye chamber. This could be proven in a rabbit model. ${ }^{15}$

The question if endophthalmitis can be transmitted via donor corneas in properly performed organ culture has not yet been answered. To the best of our knowledge, this study seems to be the first to report on the clinical course of transplanted corneas from septic donors stored in long-term organ culture. Longterm organ culture at $+30-37^{\circ} \mathrm{C}$ not only allows the growth of pathogens but also a maximal antibiotic effect. ${ }^{16}$

Contamination rates of donor corneas from septic donors stored in long-term organ culture vary in the literature. Armitage et al ${ }^{17}$ reported an overall loss of donor corneas through microbiologic contamination of $5 \%$ with a marked influence of the donor's cause of death: when the cause of death was cardiovascular disease or cerebrovascular accident, the rate of culture medium contamination was statistically significantly 
reduced, whereas donor corneas from donors who had died from systemic infection were statistically significantly more likely to be contaminated. Correspondingly, Sistani et al found a 40-fold higher incidence of culture medium contamination in septic donors: five of 20 donor corneas from septic donors were contaminated vs two of 334 donor corneas from non-septic donors. ${ }^{18}$ We could not confirm these findings. Our results show no statistically significant difference between the rate of culture medium contamination in septic and in non-septic donors.

The discarding rate, however, was statistically significantly higher in septic than in non-septic donors. This may in part be explained by the prefinal systemic catabolic situation in septic donors, which also may affect corneal endothelial cells. The various reasons for discarding, though, were not statistically different between septic and non-septic donors. Endothelial damage was the main discarding reason in both septic and non-septic donors (67\% and 58\%), which may speak in favour of the hypothesis of a metabolically more stressed endothelium in the septic group.

Our results show that there is no correspondence between the pathogens isolated from contaminated organ culture medium and the pathogens that caused sepsis in the donor. Contamination of a donor cornea via aqueous or limbal circulation has been discussed, but seems to be quite unlikely according to Clark et al. These authors were able to demonstrate that no sample of aqueous humor derived from 50 septic donors had been contaminated. ${ }^{6}$ Theoretically, bacterial contamination of the aqueous can occur when the blood-aqueous barrier has broken down, for example in bacterial meningitis at the time of death. ${ }^{6}$ In our series no donor died from bacterial meningitis. Since cadaver eyes are usually contaminated by bacteria, contamination via conjunctiva seems to be the most likely source of graft and culture medium contamination. ${ }^{7}$ In correspondence, five of seven medium contaminations in the septic donor group of this study revealed coagulase-negative staphylococcus, a resident pathogen of the conjunctiva. Two of seven contaminations revealed yeast. These pathogens did not correspond in any case to the pathogens responsible for donor sepsis. In the clinical follow-up no endophthalmitis was observed in any patient.

It remains to discuss the theoretical possibility of enhanced frequency of immune reactions with grafts from septic donors. Lipopolysaccharides, components of gram-negative bacterial cell walls may trigger inflammatory responses in the donor cornea depending on their concentration. This may result clinically in a higher frequency of immune reactions and in an elevated endothelial cell loss. ${ }^{19}$ In this study the lipopolysaccharide content of culture media could not be determined. The rate of immune reactions and the rate of graft failure, however, did not statistically significantly differ between the septic and the nonseptic group. The individual cell loss index also revealed no higher decrease of endothelial cell density in transplanted corneas from septic donors.

In conclusion it could be shown, that transmission of pathogens from septic donors via donor corneas seems to be very unlikely if long-term organ culture and corneal evaluation are performed properly. Accordingly septic donors have not to necessarily be excluded any longer from cornea donation, and, such donors may contribute to partly overcome corneal graft shortage in Germany.

\section{References}

1 Beyt BE, Waltman SR. Crytococcal endophthalmitis after corneal transplantation. N Engl J Med 1978; 298: 825-826.

2 Le Francois M, Baum JL. Flavobacterium endophthalmitis following keratoplasty. Use of a tissue culture medium stored cornea. Arch Ophthalmol 1976; 94: 1907.

3 Khodadoust AA, Franklin RM. Transfer of bacterial infection by donor cornea in penetrating keratoplasty. Am J Ophthalmol 1979; 87: 130-132.

4 Gandhi SS, Lamberts DW, Perry HD. Donor to host transmission of disease via corneal transplantation. Surv Ophthalmol 1981; 25: 306-311.

5 Keates RH, Mishler KE, Riedinger BS. Bacterial contamination of donor eyes. Am J Ophthalmol 1977; 84 617-619.

6 Clark WM, Heaton KT, Snider GR, Reeve RB, Caskey PJ. Donor eye contamination. Am J Ophthalmol 1982; 94: 395397.

7 Polack FM, Locatcher-Khozaro D, Gutierrez E. Bacteriologic study of 'donor' eyes. Evaluation of antibacterial treatments prior to corneal grafting. Arch Ophthalmol 1967; 78: 219-225.

8 European Eye Bank Association. European Eye Bank Association Directory, 9th edition, 2001

9 Bone RC, Balk RA, Cerra FB et al. Definitions for sepsis and organ failure and guidelines for the use of innovative therapies in sepsis. The ACCP/SCCM Consensus Conference Committee. American College of Chest Physicians/Society of Critical Care Medicine. Chest 1992 101: 1644-1655.

10 Hudde T, Reinhard T, Möller M et al. [Corneoscleral transplant excision in the cadaver. Experiences of the North Rhine Westfalia LIONS Cornea Bank 1995 and 1996] Korneosklerale Transplantatentnahme an der Leiche. Ophthalmologe 1997; 94: 780-784.

11 Hoffmann F. Perforierende Keratoplastik mit Kreuzstichnaht. Erste Ergebnisse. Klin Monatsbl Augenheilk 1978; 173: 696-700.

12 Reinhard T, Hutmacher M, Sundmacher R. Akute und chronische Immunreaktionen nach perforierender Keratoplastik mit normalem Immunrisiko. Klin Monatsbl Augenheilkd 1997; 210: 139-143.

13 Landesz M, Siertsema JV, Van Rij G. Comparative study of three semiautomated specular microscopes. J Cataract Refract Surg 1995; 21: 409-416. 
14 Böhringer D, Reinhard T, Godehardt E, Sundmacher R. Regressionsanalyse des idiopathischen

Endothelzellverlustes nach perforierender NormalrisikoKeratoplastik - Grundlage für die Langzeitanalyse von Endothelschädigungsfaktoren in einer retrospektiven klinischen Studie. Klin Monatsbl Augenheilkd 2001; 218: 412-417.

15 Yau C, Busin M, Kaufman HE. Ocular concentration of gentamicin after penetrating keratoplasty. $A m \mathrm{~J}$ Ophthalmol 1986; 101: 44-48.

16 Hagenah M, Winter R. Dekontamination menschlicher Spenderhornhäute während der Präparation und Konservierung. Klin Monatsbl Augenheilkd 1996; 209: 1-6.
17 Armitage WJ, Easty DL. Factors influencing the suitability of organ-cultured corneas for transplantation. Invest Ophthalmol Vis Sci 1997; 38: 16-24.

18 Sistani F, Hagenah M, Kloss A, Winter R. Kontamination von Spenderhornhäuten an Sepsis verstorbener Spender in der Organkultur. Ophthalmologe 1996; 93 (Suppl 1): S102.

19 Sobottka Ventura AC, Engelmann K, Dahinden C, Böhnke M. Endotoxins modulate the autocrine function of organ cultured donor corneas and increase the incidence of endothelial cell death. Br J Ophthalmol 1997; 81: 10931098 . 